\title{
Os Desafios impostos pela Pandemia Covid-19: Das Medidas de Proteção do Direito à Saúde aos Impactos na SAÚde Mental
}

\author{
The Challenges imposed by the Covid-19 \\ Pandemic: from Measures to Protect the Right \\ to Health to Impacts on Mental Health
}

\section{Los Desafíos impuestos por Pandemia Covid-19: de Medidas para Proteger el Derecho a la Salud a los Impactos en la Salud Mental}

\author{
Janaina Machado Sturza* \\ Rodrigo Tonel
}

\begin{abstract}
1 Introdução. 2 Um vasto e temeroso cenário: a ética da quarentena sob a perspectiva da moral e da eficácia. 3 Do mais severo ao mais brando: os impactos das medidas de segurança na saúde mental. 4 As diferentes respostas diante das diferentes situações impostas pela pandemia. 5 Iguais ou diferentes: os diversos cenários durante a pandemia. 6 Considerações finais. Referências.
\end{abstract}

\footnotetext{
* Pós Doutora em Direito pela Unisinos. Doutora em Direito pela Universidade de Roma Tre/Itália. Mestre em Direito pela Universidade de Santa Cruz do Sul - Unisc. Especialista em Demandas Sociais e Políticas Públicas também pela Unisc. Professora na Universidade Regional do Noroeste do Estado do Rio Grande do Sul - Unijui, Lecionando na Graduação em Direito e no Programa de PósGraduação em Direito - Mestrado e Doutorado. Integrante da Rede Iberoamericana de Direito Sanitário. Integrante do Comitê Gestor da Rede de Pesquisa em Direitos Humanos e Políticas Públicas. Integrante do Grupo de Pesquisa Biopolítica e Direitos Humanos (Cnpq). Pesquisadora Gaúcha FAPERGS - PqG Edital 05/2019. UNIJUI - Ijuí - RS. BR. E-mail: <janasturza@hotmail.com>.http://orcid.org/0000-0001-9290-1380

"Mestre em Direito pelo Programa de Pós Graduação - Mestrado e Doutorado em Direitos Humanos da Universidade Regional do Noroeste do Estado do Rio Grande do Sul - UNIJUI, com bolsa CAPES. Bacharel em Direito. UNIJUI - Ijuí - RS- BR. E-mail: <tonelr@yahoo.com>. https://orcid.org/00000003-2480-7426
} 
Os desafios impostos pela Pandemia COVID-19: das medidas de proteção do direito à saúde aos impactos na saúde mental

\title{
RESUMO
}

Objetivo: A Organização Mundial da Saúde (OMS), em 11 de março de 2020, anunciava ao mundo uma pandemia global - tratava-se de uma doença viral denominada de COVID-19. Nesse sentido, este estudo propõe-se a construir argumentos capazes de proporcionar reflexões e indagações acerca da exigência de medidas de proteção, apontadas como imperativas no controle da pandemia da COVID19, destacando-se a repercussão na vida diária das pessoas, especialmente no que se refere a direitos fundamentais como saúde, acesso a informações de qualidade e preservação do trabalho.

Metodologia: $\mathrm{O}$ presente estudo constitui-se como uma revisão bibliográfica que segue o método dedutivo. Utiliza-se de um aporte bibliográfico e doutrinário multidisciplinar e interdisciplinar.

Resultados: Verificou-se que o isolamento, o constante medo da doença e a ameaça de desemprego causam danos imensuráveis a saúde mental da população.

Contribuições: A principal contribuição desta pesquisa reside na possibilidade de refletir-se e indagar-se sobre as várias questões pertinentes a infeliz propagação deste novo coronavírus, que vem protagonizando uma rigorosa crise sanitária e humanitária, com abalos ao direito à saúde, as liberdades individuais e coletivas e aos meios de subsistência das pessoas. Apesar da notada necessidade de evitar qualquer convívio social para conter o contágio, enfrentar uma pandemia, em muitas situações seguida de uma quarentena, pode ter grande impacto na saúde mental dos indivíduos.

Palavras-chave: Crise sanitária. Crise humanitária. Pandemia. Quarentena. Saúde mental.

\begin{abstract}
Objective: The World Health Organization (WHO), on March 11, 2020, announced a global pandemic to the world - it was a viral disease called COVID-19. In this sense, this study proposes to build arguments capable of providing reflections and inquiries about the demand for protective measures, pointed out as imperative in the control of the pandemic of COVID-19, highlighting the impact on people's daily lives, especially with regard to fundamental rights such as health, access to qualified information and preservation of work.
\end{abstract}

Methodology: This study is a bibliographic review that follows the deductive method. It uses a multidisciplinary and interdisciplinary bibliographic and doctrinal contribution. 
Results: It's been verified that isolation, the constant fear of the disease and the threat of unemployment cause immeasurable damage to the mental health of the population.

Contributions: The main contribution of this research lies in the possibility of reflecting on and inquiring about the various issues pertinent to the unfortunate spread of this new coronavirus, which has been leading to a tremendous health and humanitarian crisis, with impacts on the right to health, collective and individual freedoms and people's livelihoods. Despite the noticed necessity to avoid any social interaction in order to contain the contagion, facing a pandemic, in many situations followed by quarantine, can have a major impact on the individuals mental health.

Keywords: Health crisis. Humanitarian crisis. Pandemic. Quarantine. Mental health.

\section{RESUMEN}

Objetivo: La Organización Mundial de la Salud (OMS), el 11 de marzo de 2020, anunció una pandemia mundial en el mundo: era una enfermedad viral llamada COVID-19. En este sentido, este estudio propone construir argumentos capaces de proporcionar reflexiones y consultas sobre la demanda de medidas de protección, señaladas como imperativas en el control de la pandemia de COVID-19, destacando la repercusión en la vida cotidiana de las personas, especialmente en el que se refiere a derechos fundamentales como la salud, el acceso a información de calidad y la preservación del trabajo.

Metodología: este estudio es una revisión bibliográfica que sigue el método deductivo. Utiliza una contribución bibliográfica y doctrinal multidisciplinaria e interdisciplinaria.

Resultados: se encontró que el aislamiento, el miedo constante a la enfermedad y la amenaza de desempleo causan un daño inconmensurable a la salud mental de la población.

Contribuciones: La principal contribución de esta investigación radica en la posibilidad de reflexionar y preguntar sobre los diversos temas pertinentes a la desafortunada propagación de este nuevo coronavirus, que ha estado liderando una rigurosa crisis humanitaria y de salud, con sacudidas al derecho a la salud, las libertades individuales. acciones colectivas y medios de vida de las personas. A pesar de la necesidad percibida de evitar cualquier interacción social para contener el contagio, enfrentar una pandemia, en muchas situaciones seguidas de cuarentena, puede tener un impacto importante en la salud mental de las personas.

Palabras clave: crisis de salud. Crisis humanitarian. Pandemia. Cuarentena. Salud mental. 
Os desafios impostos pela Pandemia COVID-19: das medidas de proteção do direito à saúde aos impactos na saúde mental

\section{INTRODUÇÃO}

Nas últimas décadas, a humanidade vem convivendo com um conhecimento paradoxal: o fato de poder ser o agressor e a vítima de si mesma com base em seus próprios atos e atitudes. Em outras palavras, a sociedade tem o potencial de ser a criadora de sua própria e completa aniquilação. Ao longo da história, o homem nunca foi confrontado com a devastação ambiental, terrorismo, pandemias e aniquilação nuclear como na contemporaneidade. Como sustenta Wuthnow (2010, p. 8, tradução nossa), "a verdade é que perigos graves para a existência da humanidade se tornaram um fato da vida contemporânea. A ameaça de morte em massa, devastação ambiental e até extinção humana é uma realidade alarmante."

Assim, pois, no dia 11 de março de 2020, a Organização Mundial da Saúde (OMS) declarava que a epidemia da doença viral denominada COVID-19, identificada em dezembro de 2019, em Wuhan, na China, tinha alcançado o nível catastrófico de uma pandemia global, afligindo bruscamente a vida das pessoas nas diferentes partes do mundo. A partir de então, a disseminação deste novo coronavírus não só afetou o direito à saúde, às liberdades e aos meios de subsistência das pessoas, mas também desencadeou uma crise global - ou, em outros termos, desencadeou uma severa crise sanitária e humanitária.

A reconhecida pandemia do novo coronavírus, diante do cenário de tragédias diárias espalhadas pelo mundo, exigiu atitudes mais radicais para o seu combate, e grande parte da população se viu diante de uma realidade, até então, nunca experimentada. A gravidade alcançada pela pandemia tornou-se uma ameaça à saúde pública, justificando restrições a determinados direitos, impostos pela limitação à livre circulação das pessoas.

Nesse sentido, as estratégias, veemente, adotadas por diferentes líderes políticos, traduzidas enquanto medidas de segurança, como quarentena, isolamento, distanciamento social, vigilância constante, limitação da liberdade, sob o argumento de prevenção a novos contágios, em alguns casos, acabam favorecendo a imposição de um estado de exceção - em outras situações, ainda mais graves, ditam quem deve continuar vivendo e quem deve morrer. Diante desse caótico cenário, é imprescindível afirmar, ainda, que tais medidas de segurança, impostas para prevenir a contaminação em massa da COVID-19, trouxeram várias consequências para a vida diária das pessoas, não só na perspectiva profissional, econômica e social, mas, também, sobretudo, para a saúde mental dos indivíduos.

Seguindo esse ideário, o estudo ora proposto constitui-se em uma revisão bibliográfica, baseada no método dedutivo, tendo por objetivo fomentar a reflexão acerca da necessária imposição das medidas de segurança, indicadas em detrimento da 
contenção da pandemia da COVID-19, bem como os seus impactos na rotina da população, circundando aspectos que dizem respeito a direitos fundamentais, como saúde, acesso a informações que correspondam à fidedigna realidade e, por fim, mas não menos importante, a preservação do trabalho sob a perspectiva econômica de manutenção da subsistência - a partir de uma análise fundamentada na saúde mental dos indivíduos.

No limiar desses objetivos, muitas indagações emergem em um contexto de luta pela própria sobrevivência, afinal, a vida no planeta está em risco, e, mais do que nunca, a sua preservação tornou-se um desafio diário à espécie humana. Afinal, quem morrerá e quem sobreviverá nesta pandemia? Diante desse cenário temeroso, no qual a disseminação de informações indevidas são um desserviço para a população, a ética e a moral, conceitos tão subjetivos e essenciais à vida em sociedade, estarão presentes no discurso que ecoa em defesa da eficácia da quarentena? Sendo a quarentena, dentre outras formas de isolamento e distanciamento, uma medida de segurança imprescindível para este momento, quais serão seus efeitos na saúde mental da população, exaltando-se neste quadro o agravamento do desemprego e a ampliação da vulnerabilidade? Em que pese à natureza democrática e global do vírus, não se tem absolutamente nenhuma resposta precisa e certeira para todas essas questões, sabe-se, apenas, que tais respostas serão produzidas de forma diferenciada, de acordo com a estrutura social, política e jurídica de cada sociedade - e, ao final, a questão comum será encontrar uma maneira de garantir que todos tenham como respirar (e sobreviver!).

Muito embora seja possível observar, diariamente, que a pandemia está aferindo não somente a habilidade de as nações e seus governantes lidarem com as situações impostas pelo coronavírus, mas também a capacidade de resiliência de toda uma população mundial, as medidas excessivas que violam os direitos mais fundamentais e humanos sob o argumento de proteção à vida - para aquelas vidas que ainda ostentam determinado potencial de preciosidade para o Estado, engendrando o pretexto ideal para a disseminação de um permanente Estado de Exceção (lê-se medo), além das fake news e toda a sua pirotecnia, apregoam o pânico na população e, por conseguinte, estimulam o adoecimento mental e emocional, sendo que os grupos mais impactados são, notoriamente, aqueles já adjetivados como vulneráveis.

\section{UM VASTO E TEMEROSO CENÁRIO: A ÉTICA DA QUARENTENA SOB A PERSPECTIVA DA MORAL E DA EFICÁCIA}

O cenário e o prognóstico do mundo real para o futuro pontualmente não são promissores. A constante lembrança e consciência das crises, além das possibilidades de eventos caóticos, levaram os governos e as sociedades a tentarem encontrar soluções ou, 
Os desafios impostos pela Pandemia COVID-19: das medidas de proteção do direito à saúde aos impactos na saúde mental

nos piores cenários, buscarem medidas que, pelo menos, possam reduzir os efeitos de possíveis crises. No entanto, o ponto a ser enfatizado nesse contexto é o fato de que as respostas - ou as ações - propostas contra eventos caóticos são frequentemente muito agressivas. Por exemplo, o mundo gasta "[...] bilhões travando a Guerra Fria, bilhões na luta contra o terrorismo e bilhões em vacinas e pesquisas médicas." (WUTHNOW, 2010, p. 1, tradução nossa).

Nesse sentido, a propensão a agir em meio a eventos catastróficos é dada por razões psicológicas, culturais e/ou sociais. Quando as pessoas são informadas sobre possíveis ameaças futuras, imediatamente, respondem com algum tipo de ação na tentativa de evitar a catástrofe e de se proteger. Por exemplo, se surgir um boato de guerra, as pessoas já entram em ação e constroem bunkers; se se prevê uma devastação ambiental, estocam comida e água em seus porões; se uma nova pandemia entra em cena, compram máscaras faciais, medicamentos e isolam-se em seus lares. A propósito, este último exemplo tem sido observado em todo o mundo, logo na sequência em que o público recebeu as informações sobre a disseminação do novo Coronavírus e sua forma de contágio. As pessoas compraram máscaras faciais, luvas cirúrgicas e álcool gel em grandes quantidades, deixando muitas prateleiras farmacêuticas totalmente vazias. Obviamente que nem todos se envolvem em algum tipo de ação, mas considera-se que a maioria das pessoas age de uma maneira ou de outra. $\mathrm{O}$ governo e a sociedade, como um todo, passam a agir imediatamente. Nesse contexto, Wuthnow (2010, p. 224, tradução nossa) acredita que "[...] a ação não apenas confirma nossa humanidade. É a nossa maneira de lutar contra a fragilidade de nossas vidas e de nosso planeta. É nosso melhor esforço para preservar o que mais prezamos."

No que diz respeito à questão das pandemias, ao longo da história, a humanidade testemunhou um vasto e temeroso cenário de doenças e devastação da saúde de diferentes povos, em diferentes partes do mundo. A Peste Ateniense de 430 a.C., a Peste Antonina, a Peste Justiniana, a Peste Negra, a Gripe Espanhola, a pandemia do HIV, a SARS, a Tuberculose (WELFORD, 2018), a Varíola, o Sarampo, o Tifo (SCHEIDEL, 2017), a H5N1, a Gripe Suína H1N1, a síndrome respiratória do Oriente Médio MERS -, o surto de Ebola, o vírus do Zika (ELBE, 2018) e, mais recentemente, a COVID-19 (WORLD HEALTH ORGANIZATION, 2020) - uma grande aniquiladora de vidas e causadora de uma crise sanitária e humanitária sem precedentes.

Assim, com o surgimento de uma nova cepa de Coronavírus em Wuhan, China, no final do ano de 2019, e sua respectiva disseminação pelo mundo em 2020, a nova pandemia colocou o planeta (ou quase todo) sob o regime de isolamento, o que fez ser declarada emergência de saúde pública de interesse internacional. A COVID-19 - como assim é também chamado o Coronavírus - "[...] é um vírus respiratório que se espalha principalmente por gotículas geradas quando uma pessoa infectada tosse ou espirra, ou 
por gotículas de saliva ou secreção nasal." (WORLD HEALTH ORGANIZATION, 2020, online, tradução nossa). O referido vírus pode infectar qualquer pessoa, no entanto, observa-se que idosos e pessoas em condições médicas preexistentes, como doenças cardíacas, asma, diabetes, entre outras, tendem a ser mais propensas e vulneráveis ao vírus, e os sintomas se manifestam de forma mais severa e os riscos de morte aumentam, respectivamente (WORLD HEALTH ORGANIZATION, 2020).

Essa nova pandemia colocou o planeta em isolamento e, em algumas situações, em quarentena. Essas medidas representam alternativas para reduzir os contágios entre as pessoas, uma vez que os cientistas não dispõem de indícios contundentes em termos de medicamentos que possam apresentar efeito curativo àqueles indivíduos já diagnosticados com COVID-19, tampouco, ainda não conseguiram desenvolver algum tipo de vacina para prevenir novas infecções. Ainda assim, pesquisadores de todo o mundo ainda estão estudando o vírus e fazendo pesquisas na tentativa de encontrar uma possível cura ou vacina para sua respectiva prevenção o mais rápido possível.

Por hora, o que os líderes políticos estão adotando em suas nações, com o objetivo de reduzir as infecções entre as populações, é basicamente o distanciamento social com o slogan Fique em Casa - devido ao fato de o vírus ser transmitido por contato físico, como aperto de mãos, abraços, tosses, espirros ou simplesmente a natural respiração perto de alguém infectado. Então, seriam a quarentena, o isolamento e as outras formas de distanciamento social as únicas soluções para proteger a população do vírus?

Antes de ir para uma tentativa de resposta a essa pergunta, é necessário fazer uma diferenciação entre os termos ${ }^{1}$. Segundo os Centros de Controle e Prevenção de Doenças (CENTERS FOR DISEASE CONTROL AND PREVENTION, 2017), a

\footnotetext{
${ }^{1}$ Em meio à pandemia do novo coronavírus pelo mundo, uma das grandes dúvidas está na diferença entre quarentena e isolamento. De acordo com a Portaria no 356/3020 do Ministério da Saúde, a quarentena tem como objetivo garantir a manutenção dos serviços de saúde em local certo ou determinado A medida é um ato administrativo, estabelecido pelas secretarias de Saúde dos estados e dos municípios ou do ministro da Saúde, e quem determina o tempo são essas autoridades. "A medida é adotada pelo prazo de até 40 dias, podendo se estender pelo tempo necessário", diz o documento. Já o isolamento serve para separar pessoas sintomáticas ou assintomáticas, em investigação clínica e laboratorial, de maneira a evitar a propagação da infecção e da transmissão. Neste caso, é utilizado o isolamento em ambiente domiciliar, podendo ser feito em hospitais públicos ou privados. Ainda segundo a norma do Ministério da Saúde, o isolamento é feito por um prazo de 14 dias - tempo em que o vírus leva para se manifestar no corpo - podendo ser estendido, dependendo do resultado dos exames laboratoriais. Casos suspeitos que estão sendo investigados também devem ficar em isolamento. Se o exame der negativo, a pessoa é liberada da precaução. "O isolamento não é obrigatório, não vai ter ninguém controlando as ações das pessoas. Ele é um ato de civilidade para a proteção das outras pessoas", orientou o secretário de Vigilância em Saúde do Ministério da Saúde, Wanderson de Oliveira. Já a quarentena, segundo o Ministério da Saúde, é uma medida obrigatória, restritiva para o trânsito de pessoas, que busca diminuir a velocidade de transmissão do novo coronavírus. Ambas são medidas de saúde pública consideradas fundamentais para o enfrentamento da pandemia Covid-19 (MELO, 2020, online).
} 
Os desafios impostos pela Pandemia COVID-19: das medidas de proteção do direito à saúde aos impactos na saúde mental

palavra quarentena refere-se à separação e à restrição de movimento entre pessoas que foram expostas a algum tipo de doença contagiosa, a fim de demonstrar com exatidão se estão doentes ou não. É interessante ressaltar que a quarentena não significa o mesmo que isolamento, este, por sua vez, se refere à separação de pessoas cujos diagnósticos já foram positivos para algum tipo de doença contagiosa. Mesmo assim, os dois termos são frequentemente usados de forma intercambiável, especialmente quando se trata dentro de uma linguagem de comunicação para o público (BROOKS et al., 2020).

Nessa mesma linha de análise, Upshur (2003) alude que a quarentena levanta duas preocupações éticas que têm a ver justamente com sua justificação no campo da moral e da eficácia. A primeira refere-se à obrigação moral de impedir que as pessoas contraiam novas infecções por um determinado vírus ou doença. Para tornar suas afirmações mais claras, o referido autor estabelece quatro princípios fundamentais para a justificação da quarentena. $O$ primeiro princípio, também chamado princípio do dano, propõe que, embora a quarentena possa representar um encolhimento de certos direitos e liberdades, em algumas situações, ainda pode ser justificada e permitida, especialmente quando os países contemplam leis de saúde pública especificadas para a adoção de quarentena. Além disso, outro aspecto a ser considerado ao justificar a quarentena é que a doença deve se espalhar/transmitir de pessoa para pessoa. Portanto, aquelas doenças que não apresentam essa característica, consequentemente, não justificam a adoção da quarentena.

O segundo princípio tem a ver com a ideia de proporcionalidade, que significa basicamente que "[...] as autoridades de saúde pública devem usar as medidas menos restritivas proporcionais ao objetivo de alcançar o controle da doença.” (UPSHUR, 2003, online, tradução nossa). Dessa forma, as autoridades devem primeiro adotar os meios e as sanções menos restritivas possíveis e apenas aumentar sua intensidade assim que se tornarem necessárias. Portanto, o uso de dispositivos, como câmeras de vigilância, policiamento, multas e, até mesmo, encarceramento, devem ser adotados em casos extremos.

O terceiro princípio refere-se à reciprocidade, ou seja, enquanto os indivíduos têm suas liberdades limitadas durante uma quarentena, por outro lado, a sociedade e o governo têm a obrigação de fornecer as comodidades necessárias, como abrigo, alimentação e apoio psicológico. Finalmente, o último princípio, também conhecido como princípio da transparência, reflete sobre a obrigação que as autoridades de saúde pública têm de comunicar todos os motivos da adoção da quarentena (UPSHUR, 2003).

Agora, no que diz respeito à eficácia da quarentena, Upshur (2003) aponta que ela pode ser traduzida em dois objetivos principais, relacionados à ideia de tentar impedir a propagação e a infecção de algum tipo de doença, além de identificar indivíduos que apresentam algum tipo de sintoma durante o período de quarentena. 
Desse modo, esse arranjo permitiria aos profissionais de saúde proceder com a devida técnica de abordagem. Nesse contexto, Rothstein et al. (2003, p. 25, tradução nossa) sustentam que:

O isolamento é relativamente íntegro cientificamente, politicamente e socialmente. Parece fazer sentido confinar indivíduos que estão doentes com uma doença transmissível e limitar seus contatos. Nem os indivíduos afetados nem os contatos em potencial da pessoa podem se opor a essas medidas. Da mesma forma, não será complicado decidir quem isolar, onde fazê-lo ou por quanto tempo. A quarentena, no entanto, é muito complicada e levanta uma série de questões difíceis de saúde pública, leis de saúde pública e políticas públicas.

Dito isso, é possível perceber que a quarentena é uma medida baseada em uma abordagem preventiva com o objetivo de proteger a propagação de uma determinada doença e de descobrir quais indivíduos podem estar potencialmente infectados. Portanto, essa atitude de caráter mais drástico deve ser autorizada como último recurso. Assim, Bensimon e Upshur (2007) acreditam que o maior desafio para as autoridades de saúde pública, durante uma pandemia, é justamente decidir se a quarentena é ou não a ação correta e mais apropriada a ser tomada, levando em consideração que a quarentena representa claramente uma significativa depravação da liberdade, o que, substancialmente, pode causar sofrimento e danos à saúde mental dos indivíduos que passam por tais restrições.

\section{DO MAIS SEVERO AO MAIS BRANDO: OS IMPACTOS DAS MEDIDAS DE SEGURANÇA NA SAÚDE MENTAL}

Dependendo do ponto de vista, a quarentena pode ser considerada como uma boa medida ou uma medida ruim. Em outras palavras, "[...] muitas pessoas acreditam que a quarentena constitui uma diminuição injustificada da liberdade pessoal, enquanto outros a veem como um aspecto integrante do controle de doenças transmissíveis." (UPSHUR, 2003, online, tradução nossa). Naturalmente que, por suas próprias naturezas, a quarentena e o isolamento têm o poder de amplificar os aspectos mentais e emocionais das pessoas. Nesse sentido, Brooks et al. (2020, p. 912, tradução nossa) sinalizam que

a quarentena é frequentemente uma experiência desagradável para quem passa por ela. A separação dos entes queridos, a perda de liberdade, a incerteza sobre o status da doença e o tédio podem, ocasionalmente, criar efeitos dramáticos. Tem sido relatado o suicídio, raiva substancial gerada e ações judiciais após a imposição de quarentena em surtos anteriores. Os benefícios potenciais da R. Opin. Jur., Fortaleza, ano 18, n. 29, p.1-27, set./dez. $2020 \bullet 9$ 
Os desafios impostos pela Pandemia COVID-19: das medidas de proteção do direito à saúde aos impactos na saúde mental

quarentena de massa obrigatória precisam ser ponderados com cuidado em relação aos possíveis custos psicológicos. O uso bem-sucedido da quarentena como medida de saúde pública exige que reduzamos, tanto quanto possível, os efeitos negativos associados a ela.

Os estressores, durante a quarentena, também podem depender de sua duração, ou seja, quanto maior a quarentena, mais impactos ela pode causar à saúde mental. Brooks et al. (2020, p. 916, tradução nossa) indicam que "[...] aqueles em quarentena por mais de 10 dias apresentaram sintomas de estresse pós-traumático significativamente mais altos do que aqueles em quarentena por menos de 10 dias." Também existem outros fatores, como a frustração e o tédio, devido ao fato de, durante uma quarentena, as pessoas serem refreadas de suas atividades diárias normais, do contato social e físico, então, por consequência, a frustração e o tédio são proporcionalmente exacerbados.

Além disso, suprimentos inadequados, como a falta de comida, água potável, roupas e abrigo durante uma quarentena, comprometem fundamentalmente a saúde mental dos indivíduos, intensificando os sentimentos de ansiedade e raiva. Ademais, informações inadequadas ou insuficientes, por parte das autoridades de saúde pública, contribuem para empobrecer a saúde mental dos indivíduos, deixando o público em um estado de confusão e incerteza (BROOKS et al., 2020).

Adicionalmente, é interessante notar a existência de problemas socioeconômicos após a quarentena, entre eles, a perda financeira é um problema bastante significativo durante uma quarentena, porque muitas pessoas precisam interromper suas atividades profissionais, obstruindo, consequentemente, suas fontes de renda. $O$ impacto da questão econômica, do mesmo modo, é considerado um grande contribuinte para o desenvolvimento de distúrbios psicológicos, demostrando efeitos negativos na saúde mental dos indivíduos, mesmo durante vários meses após uma quarentena (BROOKS et al., 2020).

Brooks et al. (2020, p. 919, tradução nossa) afirmam que a quarentena "tem um impacto psicológico considerável para os afetados.” Da mesma forma, existem outras alternativas menos prejudiciais do que a quarentena, como distanciamento social, fechamento de universidades e escolas, cancelamento de reuniões públicas, conscientização da população sobre a prevenção da doença, entre outras medidas. Os referidos autores sugerem que, havendo imprescindível necessidade de adoção de uma quarentena, esta deva ser adotada o mais breve possível, de modo que, dessa maneira, seja possível reduzir riscos para problemas psicológicos e mentais presentes e futuros.

Além disso, informações atualizadas sobre a pandemia devem estar disponíveis para todos, garantindo ao público uma melhor compreensão da doença, bem como os motivos da quarentena. Infelizmente, com a eclosão e o avanço da COVID-19 em todo o mundo, 
[...] fatalismos, teorias da conspiração, discursos de descrédito e de pânico circulam diariamente pelos principais meios de comunicação do Brasil e do mundo, sobretudo nas novas mídias sociais, escancarando, mais uma vez, a utilização de fake news como instrumento de desinformação (WERMUTH; MORAIS, 2020, p. 4).

Tais informações têm o potencial de confundir a população, contribuindo para o caos, o pânico, a confusão, a bagunça e as falsas crenças. De fato, quando ocorrem eventos caóticos, como pandemias, terrorismo, devastação ambiental e acidentes nucleares, a maneira como a sociedade e os governos geralmente abordam essas questões nem sempre é baseada no escopo científico - afinal, também é um comportamento social e cultural. Portanto, falsas informações, como a disseminação de fake news sobre um determinado assunto, são alguns dos efeitos colaterais sociais e culturais que acompanham ou vêm logo após um evento devastador.

No mesmo sentido, Huremović (2019, p. 95-96, tradução nossa) concorda que

os afetados pela quarentena, independentemente do seu estado de saúde, provavelmente reportarão sofrimento devido ao medo e à percepção de risco. Seu sofrimento pode ser amplificado diante de informações e comunicações pouco claras, comuns no período inicial de surtos de doenças.

O pânico disseminado pelas telas de TV, pela Internet, pelo rádio, entre tantos outros meios de comunicação, está causando efeitos devastadores na vida das pessoas. Os líderes políticos, em seus vocabulários, frequentemente escolhem palavras e expressões, como guerra, inimigo invisivel, ameaça oculta, entre outros, destacando a ideia de uma luta constante (BLOW, 2020). Um dos impactos causados pela mídia ao alarmar constantemente o público a ficar em casa e ao apresentar dados estatísticos de novas infeções e óbitos é que muitos pacientes crônicos que precisam de assistência e tratamento médico estão evitando comparecer nos hospitais simplesmente porque temem ser infectados pelo novo coronavírus. No Brasil, por exemplo, houve o relato de um paciente que morreu de parada cardiorrespiratória por ficar muito tempo em casa ao invés de imediatamente buscar auxílio médico no hospital. Além disso, comumente, os pacientes que vão ao hospital tendem a disfarçar os problemas respiratórios porque temem ser diagnosticados com o novo coronavírus e, consequentemente, condenados ao isolamento (MENEZES, 2020).

Os anúncios sobre o novo coronavírus são desproporcionais e, ao invés de proporcionar auxílio informativo para que a população possa melhor compreender o vírus e a doença, acabam por disseminar o pânico. Uma das razões é o sensacionalismo, isto é, uma estratégia bem-sucedida para obter mais audiência e vender mais jornais, por 
Os desafios impostos pela Pandemia COVID-19: das medidas de proteção do direito à saúde aos impactos na saúde mental

exemplo. O surto da COVID-19 representa uma grande oportunidade para os canais de televisão lucrarem, e, consequentemente, eles acabam, por vezes, exagerando naquilo que estão anunciando (DUAN; LINDER; HUREMOVIĆ, 2019). Khan e Huremović (2019, p. 40, tradução nossa) observam que as pandemias

[...] incluem não apenas a disseminação de doenças físicas, mas a disseminação de propaganda racista, anti-semita, homofóbica e propaganda pró-violência, agendas límbicas que servem para permitir que nossos desejos agressivos sejam simultaneamente saciados e projetados no outro e destruídos sem culpa.

Todavia, Fischhoff (2020, online, tradução nossa) sugere que as pessoas sigam as informações fornecidas pela Organização Mundial da Saúde (OMS) e por instituições confiáveis de seus países, simplesmente porque estas organizações "[...] fazem o melhor trabalho possivel para coletar e comunicar as informações. Isso também irá protegê-lo dos irresponsáveis, dos boatos, das pessoas que estão usando isso como uma oportunidade de vender coisas ou de inflamar o ódio racial ou étnico."

Doherty (2013), em seu guia prático Pandemics: what everyone needs to know, recomenda que, durante qualquer tipo de pandemia, as melhores fontes a serem seguidas são as designadas pelos serviços públicos de saúde. Por outro lado, o referido autor também sugere a necessidade de consultar os sites oficiais dos governos e prestar atenção aos "[...] conselhos dados pelas autoridades responsáveis na TV e no rádio. Evite fontes de informação duvidosas e 'formadores de opinião' que possam estar seduzidos por interesses comerciais, agendas políticas extremistas ou simplesmente latindo como loucos." (DOHERTY, 2013, p. 188, tradução nossa).

Outro ponto que merece ser salientado é que a quarentena e o isolamento também podem servir como solo fértil para o suicídio. A falta de vínculos sociais durante as referidas medidas não apenas aumenta as possibilidades de adoecimento mental e emocional, como também aumenta as chances de suicídio. Essas foram as análises feitas por Durkheim (2011) há mais de um século, sugerindo que a fragilização dos laços sociais constitui uma das principais razões de as pessoas cometerem suicídio precisamente, o que ele chamou de suicídio egoísta. Portanto, o fenômeno do suicídio pode aumentar potencialmente durante esses períodos de confinamento, uma vez que os níveis de integração que os indivíduos estão vinculados na sociedade são drasticamente reduzidos. Ademais, Mannix, Lee, Fleegler (2020, online, tradução nossa) sinalizam que

o distanciamento físico, a principal intervenção em saúde pública para limitar a disseminação da COVID-19, também tem o potencial de agravar o isolamento social, um conhecido fator de risco para a depressão e o suicídio. Os efeitos do distanciamento físico de curto prazo não foram bem estudados, mas o isolamento social pode 
aumentar o risco de vários problemas de saúde, incluindo doenças cardíacas, depressão e demência, que por sua vez podem desencadear comportamentos suicidas.

Por esse segmento, Reger, Stanley e Joiner (2020) alertam que, embora medidas de distanciamento social funcionem contra a disseminação do coronavírus, elas também podem servir como um combustível poderoso para levar as pessoas ao suicídio. Portanto, é um fato preocupante que aquelas estratégias que implicam distanciamento social como forma de prevenção da COVID-19 também possam criar o cenário perfeito para eventuais mortes por suicídio. Deve-se enfatizar também que o sentimento de solidão aumenta proporcionalmente e pode levar as pessoas a contemplar a possibilidade de suicídio.

Portanto, para atenuar esses efeitos e impedir o suicídio, a Internet, aliada aos dispositivos de comunicação, pode proporcionar a conexão virtual, garantindo uma sensação temporária de alívio em virtude das "companhias virtuais". Em vista da falta de contato físico e social durante a pandemia de Coronavírus, o mundo virtual particularmente as mídias sociais- tem sido muito útil como forma de manter a comunicação entre as pessoas. A tecnologia da comunicação de hoje permite que pessoas distantes interajam em tempo real, portanto, servindo como uma ferramenta importante para diminuir os sentimentos de ansiedade, tristeza e tédio.

Ainda assim, Bensimon e Upshur (2007, online, tradução nossa) alertam que, "[...] em uma sociedade democrática, a competência não pode ser legitimamente limitada e deixada a especialistas científicos." Isso significa que o conhecimento técnico e científico não é a única voz a ser ouvida durante um desastre, como no caso de uma pandemia, por exemplo. Quando um estado democrático apenas destaca seus técnicos e especialistas e orienta estritamente toda a população a seguir - até mesmo, a obedecer suas instruções, a democracia pode ficar comprometida, ou seja, como se o que eles estão dizendo, por meio de seu jargão técnico-científico, configure uma verdade absoluta. Portanto, "[...] as melhores soluções podem ser identificadas pelo fato de que elas não precisam ser escolhidas porque resultam de um conhecimento objetivo das coisas, que é uma questão de conhecimento especializado e não de escolha popular." (RANCIÈRE, 2006, p. 78, tradução nossa). No entanto, é imperativo

[...] reconhecer e legitimar uma noção mais ampla de eficácia - uma que transcenda a concepção dominante de que deriva de um conjunto de dados comprovados e verificáveis para uma que dê voz a perspectivas, experiências, preferências e compromissos culturais não científicos e não técnicos. Tais esforços são essenciais e não acidentais (BENSIMON; UPSHUR, 2007, online, tradução nossa). 
Os desafios impostos pela Pandemia COVID-19: das medidas de proteção do direito à saúde aos impactos na saúde mental

Por outro lado, não se pretende propor que a quarentena nunca seja adotada caso contrário, permitir que uma pandemia como a COVID-19 se espalhe e infecte mais pessoas, logicamente, poderá causar efeitos ainda mais drásticos do que a própria quarentena. No entanto, o que se propõe discutir, com este estudo, diz respeito à adoção da quarentena enquanto uma resposta proporcional à pandemia do novo coronavírus - afinal, a quarentena também é uma medida de restrições de direitos individuais e coletivos.

É inegável que medidas mais severas de inibição ao convívio social (incluindo o físico) têm sido amplamente reconhecidas como cruciais no combate à rápida disseminação da COVID-19. Todavia, os governos precisam adotar políticas para lidar com os danos decorrentes do confinamento e das determinações para ficar em casa, incluindo as questões pertinentes à saúde mental. Prevenir efetivamente a propagação do vírus requer um esforço conjunto entre sociedade e governo, sendo imprescindível ampla divulgação de informações de qualidade, que possam realmente contribuir e reduzir os obstáculos para os cuidados em saúde.

\section{AS DIFERENTES RESPOSTAS DIANTE DAS DIFERENTES SITUAÇÕES IMPOSTAS PELA PANDEMIA}

É possível comparar o cenário atual da questão do Coronavírus com o que Kübler-Ross (2009) havia proposto, anos atrás, em sua obra On Death and Dying, na qual ela sustentou a existência de cinco estágios essenciais sobre as reações e os comportamentos que as pessoas apresentam quando enfrentam algum tipo de doença terminal, isto é, negação e isolamento, raiva, barganha, depressão e aceitação.

No primeiro estágio, quando um paciente é diagnosticado com uma doença terminal - que acaba levando à morte - ele tende a negar o fato, desacreditando nos diagnósticos. Então, isso se intensifica, transformando-se em raiva, ou seja, quando o paciente se convence da sua situação e o fato se torna evidentemente inegável. Depois disso, chega a fase de barganha, quando o paciente deixa de lado a raiva e concorda que a morte está chegando em breve, ele tenta prolongar sua existência um pouco mais, esperando aproveitar algumas das coisas boas que a vida ainda tem para oferecer. No entanto, assim que os sintomas começam a ficar cada vez mais intensos e o paciente precisa passar por vários tipos de tratamento, enfrentando seus efeitos colaterais, a sua força de vontade pode ser reduzida relativamente, contribuindo, assim, para o estágio depressivo. Finalmente, no estágio de aceitação, o paciente apresenta um estado de ausência de sentimentos. Obviamente, esses estágios não vêm necessariamente na mesma ordem, nem todos os cinco estágios são experimentados por todos os pacientes. 
Da mesma forma, com o surto do novo Coronavírus, as respostas das nações e dos governos não têm se manifestado de maneira diferente. Žižek (2020, online, tradução nossa) analogicamente observa que,

[...] primeiro, houve uma negação (nada de grave está acontecendo, alguns indivíduos irresponsáveis estão apenas espalhando pânico); depois, raiva (geralmente de forma racista ou anti estado: os chineses sujos são culpados, nosso estado não é eficiente ...); a seguir vem a barganha $(\mathrm{OK}$, existem algumas vítimas, mas é menos grave que o SARS, e podemos limitar o dano ...); se isso não funcionar, a depressão surge (não vamos nos enganar, estamos todos condenados). Mas como seria a aceitação aqui? É um fato estranho que a epidemia mostre uma característica comum à última rodada de protestos sociais (na França, em Hong Kong ...): eles não explodem e depois desaparecem; ao contrário, eles ficam aqui e apenas persistem, trazendo medo e fragilidade permanentes para nossas vidas. Mas essa aceitação pode tomar duas direções. Pode significar apenas a re-normalização da doença: $\mathrm{OK}$, as pessoas estarão morrendo, mas a vida continuará, talvez haja até alguns bons efeitos colaterais ... Ou a aceitação pode (e deve) nos impulsionar a nos mobilizar sem pânico e ilusões, para agir em solidariedade coletiva.

Para Han (2020), os países orientais estão lidando melhor com a questão da COVID-19 do que os países ocidentais. Um dos motivos é o fato de os primeiros trabalharem com dados, vigilância digital e proteção pessoal - como máscaras, enquanto os mais recentes (países ocidentais) focam nas fronteiras e na quarentena. Outra razão pela qual a luta contra o novo coronavírus se mostrou mais promissora em países asiáticos, como Japão, China, Cingapura e Coréia do Sul, é geralmente porque eles possuem uma mentalidade autoritária que tem suas origens embutidas no sistema confucionista, e, como consequência disso, o que acontece é que, nesses países, as pessoas tendem a ser mais obedientes e depositam maior confiança em seus líderes políticos e instituições.

$\mathrm{Na}$ China, por exemplo, as pessoas são constantemente observadas e vigiadas pelos sistemas de vigilância. Toda a população chinesa é submetida a uma infraestrutura exaustiva caracterizada por câmeras com inteligência artificial, espalhadas por locais públicos, que monitoram cada passo da população. Portanto, os olhos do governo chinês veem tudo o que acontece em tempo real. Esse sistema de vigilância é tão sofisticado que é capaz, até mesmo, de medir a temperatura do corpo humano; no entanto, no contexto da luta contra o novo coronavírus, essa tecnologia tem possibilitado um exame mais minucioso da população com o fito de descobrir quem pode estar infectado pelo vírus por meio da percepção da temperatura corporal mais alta - que pode ser considerada 
Os desafios impostos pela Pandemia COVID-19: das medidas de proteção do direito à saúde aos impactos na saúde mental

uma indicação ou sintoma inicial. Apesar disso, Han (2020, online, tradução nossa) afirma que

[...] o Estado sabe, portanto, onde estou, com quem me encontro, o que faço, o que procuro, em que penso, o que como, o que compro, aonde me dirijo. É possível que no futuro o Estado controle também a temperatura corporal, o peso, o nível de açúcar no sangue etc. Uma biopolítica digital que acompanha a psicopolítica digital que controla ativamente as pessoas.

Apesar da tamanha intrusão na vida íntima da população e da ganância insaciável de controle social, Zibechi (2020, p. 116, tradução nossa) descreve que "[...] o controle social na China é sufocante: das milhões de câmeras que monitoram as pessoas ao sistema diabólico de "crédito social" que premia e remove pontos com base no comportamento correto de seus cidadãos, bem como na estigmatização e discriminação de pessoas LGBTI.”

Assim, é bastante provável que essa pesada maquinaria de vigilância não seria muito bem-vinda nos países ocidentais, principalmente porque a vida privada e a intimidade são consideradas direitos, portanto precisam ser preservadas e protegidas. É parcialmente por isso que os países europeus, por exemplo, adotam outras medidas, como o fechamento de aeroportos e fronteiras e o bloqueio de cidades.

Outra diferença entre países asiáticos e europeus é que, nos primeiros, as pessoas costumam usar máscaras faciais, enquanto, nos últimos, há a alegação de que as máscaras são simplesmente inúteis. Obviamente, há uma diferença cultural, ou seja, na Europa, prevalece o costume de as pessoas irem a todos os lugares sem máscaras faciais e, por exemplo, se alguém aparecer vestindo máscaras em locais públicos, há uma chance de que essa pessoa logo se sinta muito desconfortável devido aos olhares de seus semelhantes que a encaram com certa surpresa. Ao contrário, na Coréia, por exemplo, a maioria da população usa máscaras em locais públicos - mesmo no trabalho - como um método defensivo contra o vírus, e, se alguém se dirigir a espaços públicos com o rosto descoberto, provavelmente será repreendido (HAN, 2020).

Santos (2020) reconhece que países asiáticos, como a China, operaram com métodos repressivos e um forte aparato de vigilância para lidar com o vírus, obtendo resultados mais eficientes e reduzindo, significativamente, a velocidade de infecção, quando comparados aos países democráticos. No entanto, isso não significa que as democracias não sejam eficazes no que concerne ao tratamento de pandemias, afinal, teoricamente, as pandemias tendem a ser menos letais nos países democráticos em prol do livre fluxo de informações. Todavia, um dos problemas nessas nações é a circulação de fake news, que têm o efeito de embaralhar o entendimento da população no tocante à pandemia e aos seus efeitos. 
Nesse cenário, assim que a crise da pandemia eclodiu, Agamben (2020) alertou contra o perigo do surgimento de um estado de exceção. O Estado, ao tomar medidas para monitorar e restringir a mobilidade sob o pretexto de combater a pandemia, adquiriria poderes excessivos que colocariam em risco a própria democracia. Nesse sentido,

[...] o estado de medo que nos últimos anos foi evidentemente se difundindo nas consciências dos indivíduos e que se traduz em uma verdadeira necessidade de estados de pânico coletivo, para o qual a epidemia mais uma vez oferece o pretexto ideal. Assim, em um perverso círculo vicioso, a limitação da liberdade imposta pelos governos é aceita em nome de um desejo de segurança que foi induzido pelos próprios governos que agora intervêm para satisfazê-lo (AGAMBEN, 2020, online).

Nessa perspectiva, Agamben (2004. p. 42), especifica que “[...] o estado de exceção moderno é, ao contrário, uma tentativa de incluir na ordem jurídica a própria exceção, criando uma zona de indiferenciação em que fato e direito coincidem." $\mathrm{Na}$ Itália, por exemplo, foi promulgado o Texto Coordenado do Decreto-Lei a partir de 23 de fevereiro de 2020, n. 6, que adota medidas urgentes de contenção e manejo da emergência epidemiológica da COVID-19, proibindo expressamente o acesso a municípios ou a áreas afetadas, assim como a retirada de pessoas desses locais; a suspensão de manifestações ou iniciativas de qualquer natureza, eventos e reuniões em local público ou privado; a interrupção de serviços e atividades educacionais, como em escolas e universidades - exceto atividades virtuais; o cancelamento e o fechamento de institutos culturais e locais públicos; a suspensão de todas as viagens educacionais, nacionais e internacionais; a cessação de processos de concurso e atividades de órgãos públicos - exceto aqueles listados como serviços essenciais, que representam utilidade pública; a aplicação da medida de quarentena com vigilância ativa nos indivíduos que eventualmente tiveram contato próximo com casos confirmados de coronavírus (TESTO..., 2020).

Diferentemente de algumas das políticas europeias e asiáticas contra o coronavírus, o Brasil vem adotando uma postura política diversa. Em termos de ações, o Brasil propõe abordagens semelhantes àquelas instituídas por outros países, como o distanciamento social, restringindo o acesso a determinadas áreas, como praias e locais públicos, o toque de recolher em alguns Estados, entre outras medidas. Em relação ao escopo jurídico, a adoção da Lei n. ${ }^{\circ} 13.979$, de 6 de fevereiro de 2019, especificamente em seu art. $3^{\circ}$, fornece medidas para lidar com a emergência de saúde pública de importância internacional resultante do coronavírus, responsável pelo surto de 2019, autorizando a aplicação de medidas, como quarentena, isolamento, pesquisa 
Os desafios impostos pela Pandemia COVID-19: das medidas de proteção do direito à saúde aos impactos na saúde mental

epidemiológica, determinação de exames médicos obrigatórios, exames laboratoriais, tratamentos médicos, vacinação, necropsia, cremação, manejo de cadáveres, restrição excepcional e temporária para rodovias, portos ou aeroportos de entrada e saída do país e transporte interestadual e interurbano, entre outros (BRASIL, 2020).

Entretanto, em termos de pronunciamento político, o presidente do Brasil, Jair Bolsonaro, fez um pronunciamento surpreendente, quando foi confrontado se as pessoas deveriam ficar em casa ou voltar a ter uma vida normal dedicando-se as suas atividades de rotina, respondeu: "Alguns vão morrer? Vão, ué, lamento. Essa é a vida" (MOTA, 2020, online). Claramente, é bastante distinguível que as principais preocupações do presidente brasileiro estejam relacionadas à economia do país, e não à vida humana. Afinal, ele alegou que o novo coronavírus se trata apenas de uma gripezinha que afeta apenas os idosos e que a maioria da população não deveria se preocupar com isso, mas deveria imediatamente voltar ao trabalho ao invés de ficar em casa sem fazer nada.

Apesar do conteúdo do pronunciamento do presidente brasileiro, Mbembe (2020) manifestou sua opinião durante uma entrevista, sugerindo que esse tipo de discurso corresponde ao conceito de necropolítica, no sentido de que é um sacrifício admissivel, por exemplo, que os idosos morram, uma vez que não apresentam um prognóstico de vida muito longo para o futuro e que suas aptidões para o trabalho estão se desvanecendo gradativamente. Por isso, segundo essas prerrogativas de análise, essa massa populacional deve ser descartada, e as prioridades de tratamento devem ser dadas aos mais jovens, uma vez que estes, ainda, disporão de muitos anos de vida para o futuro e suas forças para o trabalho funcionam como uma turbina para impulsionar a economia e garantir a existência do sistema capitalista parasitário.

Diante disso, Mbembe (2016, p. 146) define a necropolítica nos seguintes termos: "[...] formas contemporâneas que subjugam a vida ao poder da morte (necropolítica) e reconfiguram profundamente as relações entre resistência, sacrifício e terror.” Em outras palavras, o conceito de necropolítica significa "[...] a maneira como certos corpos são marcados e comercializados como vivos, vivamente e merecedores de vida, em que outros corpos são vistos como já mortos ou destinados à morte: suas vidas são de pouca consequência, enquanto suas mortes consolidam o poder soberano.” (MARTINBARON, 2014, p. 51, tradução nossa).

O fato de o vírus afetar o sistema respiratório já está forçando os governos a ditar quem irá respirar e quem irá sufocar. Além disso, a maioria das pessoas que morreram devido ao coronavírus nem sequer tiveram um funeral decente, sendo imediatamente enterradas ou incineradas. Membros da família, amigos e vizinhos testemunharam uma maneira muito difícil de separação de seus entes queridos. Esse é o necropoder, um poder sobre os corpos de quem vive e de quem morre. Nessa perspectiva, Mbembe 
(2020, online) questiona sobre a maneira que o governo se utiliza para desfazer-se dos corpos das pessoas que não resistiram aos efeitos do novo coronavírus e morreram,

como se fossem lixo do qual devemos nos livrar o mais rápido possível. Essa lógica de eliminação ocorre precisamente no momento em que precisamos, pelo menos em teoria, de nossa comunidade. E não há comunidade sem poder dizer adeus a quem partiu, organizar funerais. A questão é: como criar comunidades em tempos de calamidade?

Outra preocupação é que, no Brasil, inicialmente, houve uma ordem para fechar igrejas e templos de todas as denominações e religiões, devido à propagação da COVID19 e à respectiva quarentena, interrompendo temporariamente seus rituais e cerimônias. No entanto, um decreto presidencial foi anunciado, sustentando que as atividades religiosas deveriam ser permitidas, assemelhando-as aos serviços essenciais. Diante dessa permissão, a 1० Vara Federal de Duque de Caxias, no Rio de Janeiro, suspendeu a aplicação desse decreto, mais uma vez, ordenando o fechamento de todos os templos e as igrejas religiosas durante a quarentena (SANTOS, 2020).

Nesse sentido, Ahmed e Victor (2019) destacam que aspectos religiosos e culturais devem ser levados em consideração. Geralmente, a cultura e o sistema religioso de determinado país podem desempenhar um papel importante em termos de contribuição quando se trata de impedir a propagação de uma determinada doença contagiosa ao passo que, também, é possível o inverso, isto é, podendo impulsionar as taxas de infecções. Um exemplo dado pelos referidos autores é o caso do vírus Ebola, que atingiu muitas pessoas na África Central e Ocidental entre 2014 e 2016. Naquele momento, muitos indivíduos não levaram a doença a sério por causa de suas crenças religiosas e, consequentemente, não atendiam as orientações dos especialistas. Eles associavam, dessa maneira, a disseminação do vírus Ebola a algum tipo de punição enviada por sua divindade ou espíritos ancestrais, em resposta às suas transgressões. Entre outras comunidades africanas, as pessoas também não tomaram as precauções necessárias e tampouco procuraram assistência médica, mas optaram pelos chamados curandeiros. Portanto, a cultura e a religião, em certos momentos, podem representar um sério desafio em períodos de pandemia.

Mesmo assim, diante de todos os percalços e os desafios que a pandemia do novo coronavírus vem causando no mundo todo, é ainda possível encontrar alternativas como a utilização da Internet e das tecnologias de comunicação para lidar com a solidão, o tédio, a falta de contato social, a impossibilidade de participar de cerimônias religiosas, entre outros estressores durante uma quarentena. No entanto, no que diz respeito à questão econômica, quais são os impactos em termos de emprego e trabalho durante a pandemia? Quem serão os economicamente mais impactados pela quarentena? Quais os 
Os desafios impostos pela Pandemia COVID-19: das medidas de proteção do direito à saúde aos impactos na saúde mental

efeitos de uma crise econômica, provocada por uma pandemia, na saúde mental dos indivíduos?

\section{IGUAIS OU DIFERENTES: OS DIVERSOS CENÁRIOS DURANTE A PANDEMIA}

Baseado em referências históricas, Scheidel (2017) acentua, por exemplo, que, no período pré-moderno - marcado pela presença de sociedades agrárias-, toda vez que uma praga atingia a população, causava o efeito de nivelar as desigualdades entre terra e trabalho. Em outras palavras, pandemias ocasionavam uma significativa redução no valor da terra enquanto aumentava o valor do trabalho com salários mais altos. Obviamente, o referido autor partilha do entendimento de que uma pandemia funciona como um nivelador de desigualdades sociais e de riqueza, deixando os empregadores opulentos menos ricos e os trabalhadores em melhor situação. Em suas próprias palavras, "[...] as pandemias serviram assim como um mecanismo para comprimir as desigualdades de renda e riqueza que eram ao mesmo tempo extremamente brutais e, por fim, insustentáveis." (SCHEIDEL, 2017, n.p., tradução nossa).

Nesse sentido, Scheidel (2017) lembra que, quando a Peste Negra estava proliferando em toda a Europa, a Ásia Central e em alguns países africanos, entre 1334 e 1400, resultando em mais de 150 milhões de mortes, o efeito econômico era a favor dos trabalhadores - houve uma redução significativa nos preços da terra e dos alimentos e um aumento no salário dos trabalhadores, atenuando a desigualdade de riqueza e renda.

Em conjunto com a pandemia da COVID-19, Scheidel (2020) apresenta um argumento interessante. Ele alega que as mortes, infelizmente causadas pela COVID-19, têm o efeito de reduzir proporcionalmente a força de trabalho, e isso significa que os trabalhadores podem vender sua força de trabalho por salários mais altos. Então, em última análise, o resultado desse efeito dominó é a redução das desigualdades sociais.

O argumento de Scheidel parece razoável, no entanto é preciso lembrar que há um grande número de trabalhadores precários, informais e autônomos para os quais, após décadas, tendo seus direitos literalmente cortados em pedaços pelas políticas neoliberais, a nova pandemia não irá trazer efeitos econômicos positivos, pelo contrário, já está causando mais sofrimento na vida dessas pessoas. Por exemplo, as orientações dadas pelas autoridades e pelas instituições oficiais de saúde são ingenuamente incompatíveis com a realidade diária em que essas pessoas estão inseridas. Eles não podem simplesmente ficar em casa, eles têm que escolher entre ficar em casa e agir de acordo com as recomendações dadas pelas autoridades sanitárias ou sair e trabalhar para garantir o sustento. A rigor, eles precisam escolher se morrem pelo vírus ou morrem pela 
fome. Parece que as recomendações são feitas e indicadas para a classe média, que representa uma pequena porção da população mundial (SANTOS, 2020).

Além disso, é fundamental mencionar os vendedores ambulantes. Primeiro, porque a proibição de vender seus produtos nas ruas - ruas vazias, compromete sua única fonte de renda. Segundo, esses trabalhadores terão de escolher entre duas opções quando gastarão o pouco dinheiro disponível: uma é comprar insumos, como álcool gel e máscaras, e a outra é comprar comida.

E os sem-teto? Como eles recepcionam a expressão Fique em Casa? Alternativamente, o que a expressão lavar as mãos significa para as pessoas que vivem em favelas ou bairros informais, onde as condições sanitárias são caracterizadas pela falta de infraestrutura, saneamento, água e eletricidade? Diante dessas abordagens, Santos (2020, n.p.) indaga:

[...] dadas as condições de habitação, poderão cumprir as regras de prevenção recomendadas pela OMS? Poderão manter a distância interpessoal nos espaços exíguos de habitação onde a privacidade é quase impossivel? Poderão lavar as mãos com frequência quando a pouca água disponível tem de ser poupada para beber e cozinhar? O confinamento em alojamentos tão exíguos não terá outros riscos para a saúde tão ou mais dramáticos do que os causados pelo vírus?

As consequências resultantes do distanciamento social entre pessoas vulneráveis são amplas. O desemprego ou a falta temporária de trabalho e, consequentemente, a falta de dinheiro, certamente, fortalecerão o vínculo entre violência doméstica, abuso de drogas, má nutrição, falta de moradia, doença mental, violência e suicídio. A partir de agora, no contexto da pandemia da COVID-19, "[...] a probabilidade de as pessoas que sofrem os maiores custos de distanciamento social permanecerem em conformidade com as orientações de saúde pública diminuirá. Isso não é sustentável, nem é um sacrifício aceitável esperar que as pessoas façam.” (DeLUCA et al., 2020, online, tradução nossa). Sem dúvida alguma, o isolamento, o medo da COVID-19 e a eminente ameaça de desemprego causam danos imensuráveis à saúde mental da população.

\section{CONSIDERAC̣ÕES FINAIS}

A COVID-19 apresenta-se, indubitavelmente, como um ríspido teste para indivíduos, sociedades, governos e comunidades. É o momento da solidariedade, da cooperação e da empatia para combater um vírus ainda misterioso que afeta de forma agressiva a saúde não só física, mas também mental, atenuando os efeitos - com frequência involuntários, das medidas adotadas para deter sua propagação e proporcionar a proteção integral à saúde e, consequentemente, a manutenção da vida 
Os desafios impostos pela Pandemia COVID-19: das medidas de proteção do direito à saúde aos impactos na saúde mental

das populações. O respeito aos direitos humanos em todos os âmbitos, incluindo os direitos econômicos, sociais e culturais, bem como os direitos civis e políticos, mostra-se diuturnamente como fundamental para o sucesso das respostas exigidas pela saúde pública diante da pandemia e almejado (e merecido!) pela população acometida por este sinistro predador de vidas.

Então, fica evidenciado que a COVID-19 substanciou questões éticas e morais sobre as medidas preventivas que as nações estão adotando na tentativa de conter novas infecções, assim como as dificuldades que os governantes e as suas nações estão enfrentando para lidar com o vírus e a (in)efetividade de garantir o direito à saúde para todos. Do mesmo modo como os cadáveres estão sendo incinerados, a vida da população também corre o risco de ser destruída mundo afora - e não somente pela morte, mas também pelos abalos talvez irreversíveis causados à saúde mental da população.

O novo coronavírus, sem sombra de dúvidas, certamente, tem causado devastação em todo o mundo. No entanto, uma devastação ainda mais agressiva e perigosa do que o próprio vírus é a propagação de estados de exceção, o militarismo, o fascismo, a violação dos direitos humanos e fundamentais, os mecanismos exagerados e maciços de controle social, a necropolítica para ditar quem vive e quem morre - neste caso, quem respira e quem sufoca-, as desigualdades sociais e a sobreposição da economia e do lucro sobre a vida humana.

É necessário relembrar que as ditas democracias e o Estado são condições necessárias para a conquista e o respeito aos direitos humanos, e as limitações de tais direitos podem causar sérios danos aos sistemas democráticos, correspondendo às perspectivas de um estado de exceção. É reconhecido que a restrição e a limitação de certos direitos podem gerar impactos acerca de sua integral fruição, especialmente entre grupos vulneráveis, portanto é indispensável a adoção de medidas positivas de proteção adicional a favor de toda a população (COMISIÓN INTERAMERICANA DE DERECHOS HUMANOS, 2020).

É inegável que as medidas de proteção à população são mais do que necessárias e essenciais neste momento de disseminação desse vírus desconhecido e misterioso, todavia essas medidas devem ser indicadas e, em algumas situações, até mesmo, impostas, de forma responsável, coerente e bem articuladas, na intenção de realmente proteger e não de criar um contexto de pânico e histeria coletiva, no qual se verificam diariamente controvérsias no âmbito da saúde, da economia e da política nacional e internacional. O planeta já está vivenciando uma crise sanitária e humanitária, e agravar este caos, neste momento, pode ter repercussões imensuráveis na sobrevivência da humanidade. 
Portanto, retornar às indagações iniciais sobre quem morrerá e quem sobreviverá diante desta crise incondicional que acomete a contemporaneidade, seja sob a concepção da saúde mental, por meio do binômio vida/morte, seja sob a conjuntura política e econômica, por meio do binômio emprego/desemprego, significa afirmar que o cenário atual é de gravidade e, em última análise, de letalidade. O mundo está lutando pela preservação e pela manutenção da espécie humana, por vias que despendem um esforço coletivo que representa um desafio não só para os governantes, mas também, especialmente, para a sociedade e para os sistemas de saúde.

É de suma importância reafirmar que, hoje, nenhuma resposta absoluta impera sobre as hipóteses indagativas propostas, afinal, o vírus demonstra-se democrático e afeta todos sem discriminar fronteiras, gênero, classe ou raça. As respostas e as soluções para as crises geradas por esta pandemia serão produzidas de forma diversa, dentro de contextos estruturais diversos - serão construções diárias não só nos aspectos sociais, políticos e jurídicos, mas também na reorganização de vidas que merecem ser vividas com dignidade. O ponto culminante e único entre os povos será um só - sobreviver!

Por hora, tudo o que resta é lavar as mãos, usar máscaras faciais, manter o distanciamento social e esperar por um futuro melhor, no qual seja possivel manter a integridade física e mental, respirando livre e destemidamente.

\section{REFERÊNCIAS}

AGAMBEN, Giorgio. Estado de exceção. Tradução Iraci D. Poleti. São Paulo: Boitempo Editorial, 2004.

AGAMBEN, Giorgio. O estado de exceção provocado por uma emergência imotivada. Tradução Luisa Rabolini. Instituto Humanitatis Unisinos, 27 fev. 2020. Disponível em: http://www.ihu.unisinos.br/78-noticias/596584-o-estado-de-excecao-provocado-poruma-emergencia-imotivada. Acesso em: 21 abr. 2020.

AHMED, Saeed; VICTOR, Guitelle St. The importance of culture in managing mental health response to pandemics. In: HUREMOVIĆ, Damir. Psychiatry of pandemics: a mental health response to infection outbreak. Manhasset, New York: Springer, 2019. p. 55-54.

BENSIMON, Cécile M.; UPSHUR, Ross. Evidence and effectiveness in decisionmaking for quarantine. Am J Public Health, Apr. 2007. Disponível em: https://www.ncbi.nlm.nih.gov/pmc/articles/PMC1854977/. Acesso em: 2 abr. 2020.

BLOW, Charles. The politics of a pandemic. The New York Times, 29 Mar. 2020. Disponivel em: https://www.nytimes.com/2020/03/29/opinion/coronaviruspandemic-politics.html. Acesso em: 14 abr. 2020. 
Os desafios impostos pela Pandemia COVID-19: das medidas de proteção do direito à saúde aos impactos na saúde mental

BRASIL. Lei $\mathrm{n}^{\circ}$ 13.979, de 6 de fevereiro de 2020. Brasília, DF: Presidência da República, 2020. Disponível em: http://www.planalto.gov.br/ccivil_03/_ato20192022/2020/lei/113979.htm. Acesso em: 25 abr. 2020.

BRASIL. Ministério da Saúde. Painel coronavírus. 23 abr. 2020. Disponível em: https://covid.saude.gov.br/. Acesso em: 24 abr. 2020.

BROOKS, Samantha K. et al. The psychological impact of quarantine and how to reduce it: rapid review of the evidence. The Lancet, v. 395, n. 10227, p. 912-920, 14 Mar. 2020. Disponível em: https://www.thelancet.com/action/showPdf?pii=S01406736\%2820\%2930460-8. Acesso em: 1 abr. 2020.

CENTERS FOR DISEASE CONTROL AND PREVENTION. Quarantine and isolation. 2017. Disponível em: https://www.cdc.gov/quarantine/index.html. Acesso em: 1 abr. 2020.

COMISIÓN INTERAMERICANA DE DERECHOS HUMANOS. Pandemia y derechos humanos en las américas. Resolución 1/2020. Disponível em: https://www.oas.org/es/cidh/decisiones/pdf/Resolucion-1-20-es.pdf. Acesso em: 24 abr. 2020.

DeLUCA, Stefanie et al. The unequal cost of social distancing. Coronavirus Resource Center, John Hopkins University \& Medicine, 2020. Disponível em: https://coronavirus.jhu.edu/from-our-experts/the-unequal-cost-of-social-distancing. Acesso em: 23 abr. 2020.

DOHERTY, Peter C. Pandemics: what everyone needs to know. New York: Oxford University Press, 2013.

DUAN, Christy; LINDER, Howard; HUREMOVIĆ, Damir. Societal, public, and [emotional] epidemiological aspects of a pandemic. In: HUREMOVIĆ, Damir. Psychiatry of pandemics: a mental health response to infection outbreak. Manhasset, New York: Springer, 2019. p. 45-54.

DURKHEIM, Émile. O suicídio: estudo de sociologia. Tradução Mônica Stahel. 2. ed. São Paulo: Editora WMF Martins Fontes, 2011.

ELBE, Stefan. Pandemics, pills and politics: governing global health security. Baltimore: Johns Hopkins University Press, 2018.

FISCHHOFF, Baruch. Speaking of Psychology: Coronavirus Anxiety (Part 1). American Psychological Association, 2020.2 Disponivel em: https://www.apa.org/research/action/speaking-of-psychology/coronavirus-anxiety. Acesso em: 14 abr. 2020.

HAN, Byung-Chul. O coronavírus de hoje e o mundo de amanhã, segundo o filósofo Byung-Chul Han. El País, 22 mar. 2020. Disponível em: 
https://brasil.elpais.com/ideas/2020-03-22/o-coronavirus-de-hoje-e-o-mundo-deamanha-segundo-o-filosofo-byung-chul-han.html. Acesso em: 8 abr. 2020.

HUREMOVIĆ, Damir. Mental health of quarantine and isolation. In: HUREMOVIĆ, Damir. Psychiatry of pandemics: a mental health response to infection outbreak. Manhasset, New York: Springer, 2019. p. 95-118.

KHAN, Sameer; HUREMOVIĆ, Damir. Psychology of the Pandemic. In: HUREMOVIĆ, Damir. Psychiatry of pandemics: a mental health response to infection outbreak. Manhasset, New York: Springer, 2019. p. 37-44.

KÜBLER-ROSS, Elizabeth. On death and dying: what the dying have to teach doctors, nurses, clergy and their own families. London and New York: Routledge Taylor and Francis Group, 2009.

MANNIX, Rebekah; LEE, Lois K.; FLEEGLER, Eric W. Coronavirus disease 2019 (covid-19) and firearms in the united states: will an epidemic of suicide follow? Annals of International Medicine, 22 Apr. 2020. Disponivel em: https://annals.org/aim/fullarticle/2765237/coronavirus-disease-2019-covid-19-firearmsunited-states-epidemic-suicide. Acesso em: 24 abr. 2020.

MARTIN-BARON, Michelle R. (Hyper/in)visibility and the military corps(e). In: HARITAWORN, Jin et al. Queer Necropolitics. New York: Routledge Taylor \& Francis Group, 2014. p. 51-71.

MBEMBE, Achille. La pandemia democratiza el poder de matar. Lobo Suelto, 2020. Disponível em: http://lobosuelto.com/la-pandemia-democratiza-el-poder-de-matarentrevista-a-achilles-mbembe/. Acesso em: 27 abr. 2020.

MBEMBE, Achille. Necropolítica. Arte e Ensaios, n. 32, 2016. Disponível em: https://revistas.ufrj.br/index.php/ae/article/view/8993/7169. Acesso em: 10 abr. 2020.

MELO, Karine. Covid-19: saiba a diferença entre quarentena e isolamento: um é medida administrativa para manter serviços, outro é recomendação. Disponível em: https://agenciabrasil.ebc.com.br/saude/noticia/2020-03/covid-19-saiba-diferenca-entrequarentena-e-isolamento. Acesso em: 30 abr. 2020.

MENEZES, Maiá. Coronavírus: médicos temem a epidemia do medo. O Globo, 14 abr. 2020. Disponível em: https://oglobo.globo.com/sociedade/coronavirus-medicos-tememepidemia-do-medo-24358220. Acesso em: 14 abr. 2020.

MOTA, Erick. Bolsonaro sobre coronavírus: "alguns vão morrer, lamento, essa é a vida”. 28 mar. 2020. Disponível em: https://congressoemfoco.uol.com.br/governo/bolsonaro-sobre-coronavirus-alguns-vaomorrer-lamento-essa-e-a-vida/. Acesso em: 10 abr. 2020. 
Os desafios impostos pela Pandemia COVID-19: das medidas de proteção do direito à saúde aos impactos na saúde mental

RANCIÈRE, Jacques. Hatred of democracy. Translated by Steve Corcoran. New York: Verso, 2006. Disponível em: http://www.oddweb.org/wpcontent/uploads/2014/12/Ranci\%C4\%8Dre-Hatred-of-Democracy.pdf. Acesso em: 3 abr. 2020.

REGER, Mark A.; STANLEY, Ian H.; JOINER, Thomas E. Suicide mortality and coronavirus disease 2019 - a perfect storm? JAMA Psychiatry, 10 Apr. 2020. Disponível em: https://jamanetwork.com/journals/jamapsychiatry/fullarticle/2764584. Acesso em: 24 abr. 2020.

ROTHSTEIN, Mark A. et al. Quarantine and isolation: lessons learned from sars. Louisville, KY: Institute for Bioethics, Health Policy and Law, University of Louisville School of 2003.2 Disponível em: https://biotech.law.lsu.edu/blaw/cdc/SARS_REPORT.pdf. Acesso em: 2 abr. 2020.

SANTOS, Boaventura de Sousa. A cruel pedagogia do vírus. Coimbra: Almedina, 2020.

SANTOS, Rafa. Juiz suspende decreto de bolsonaro que tira igrejas e lotéricas de quarentena. Conjur, 27 mar. 2020. Disponivel em: https://www.conjur.com.br/2020mar-27/juiz-suspende-decreto-tira-igrejas-loterica-quarentena. Acesso em: 17 abr. 2020.

SCHEIDEL, Walter. The great leveler: violence and the history of inequality from the stone age to the twenty-first century. Princenton, New Jersey: Princenton University Press, 2017.

SCHEIDEL, Walter. Why the wealthy fear pandemics. The New York Times, 9 Apr. 2020. Disponível em: https://www.nytimes.com/2020/04/09/opinion/sunday/coronavirus-economyhistory.html. Acesso em: 21 abr. 2020.

TESTO Coordinato del Decreto-legge 23 febbraio 2020, n. 6. Misure urgenti in materia di contenimento e gestione dell'emergenza epidemiologica da COVID-19. 2020. Disponivel em: https://www.silpcgil.it/articolo/8180-testo_coordinato_del_decretolegge_23_febbraio_2020\%2C_n._6__recante\%3A_\%C2\%ABmisure_urgenti_in_mater ia_di_contenimento_e_gestione_dell\%27emergenza_epidemiologica_da_covid19.\%C2\%BB. Acesso em: 22 abr. 2020.

UPSHUR, Ross. The ethics of quarantine. AMA Journal of Ethics, Nov. 2003. Disponivel em: https://journalofethics.ama-assn.org/article/ethics-quarantine/2003-11. Acesso em: 2 abr. 2020.

WERMUTH, Maiquel Ângelo Dezordi; MORAIS, José Luis Bolzan de. Da exceção agambeniana à constituição planetária de ferrajoli: desafios impostos pela pandemia do novo coronavírus às categorias jurídico-políticas tradicionais. Revista Eletrônica do Curso de Direito da UFSM, v. 15, n. 1, e43057, 2020. Disponível em: 
https://periodicos.ufsm.br/revistadireito/article/view/43057/pdf. Acesso em: 4 abr. 2020.

WELFORD, Mark. Geographies of plague pandemics: the spatial-temporal behavior of plague to modern day. London and New York: Routledge Taylor \& Francis Gourp, 2018.

WORLD HEALTH ORGANIZATION. Coronavirus disease (COVID-19) advice for the public: Myth busters. 2020. Disponível em: https://www.who.int/emergencies/diseases/novel-coronavirus-2019/advice-forpublic/myth-busters. Acesso em: 7 abr. 2020.

WORLDOMETER. Covid-19 coronavirus pandemic. 24 Apr. 2020. Disponível em: https://www.worldometers.info/coronavirus/. Acesso em: 24 abr. 2020.

WUTHNOW, Robert. Be very afraid: the cultural response to terror, pandemics, environmental devastation, nuclear annihilation, and other threats. New York: Oxford University Press, 2010.

ZIBECHI, Raúl. A las puertas de un nuevo orden mundial. In: AGAMBEN, Giorgio et al. Sopa de Wuhan: pensamiento contemporáneo en tiempos de pandemias. [S.l.]: ASPO (Aislamiento Social Preventivo y Obligatorio), 2020. p. 113-118.

ŽIŽEK, Slavoj. Monitor and punish? yes, please! The philosophical salon. Disponível em: http://thephilosophicalsalon.com/monitor-and-punish-yes-please/. Acesso em: 7 abr. 2020.

\section{NOTA}

Os autores JANAÍNA MACHADO STURZA E RODRIGO TONEL exerceram funções tanto conjuntas quanto complementares para a composição do presente artigo. A pesquisa bibliográfica e a redação ocorreram prioritariamente por Rodrigo e a organização metodológica, revisão e orientação científica por Janaína. Desta forma, os autores entendem que as contribuições na construção do artigo se deram de forma coletiva.

Como citar este documento:

STURZA, Janaína Machado; TONEL, Rodrigo. Os desafios impostos pela pandemia COVID-19: das medidas de proteção do direito à saúde aos impactos na saúde mental. Revista Opinião Jurídica, Fortaleza, v. 18, n. 29, p. 1-27, set./dez. 2020. 